\title{
EPSAC for wastewater treatment process (BSM1)
}

\author{
Ruben Crisan ${ }^{a}$ \\ and Ioan $\mathrm{Nascu}^{b}$ \\ Technical University of Cluj-Napoca \\ 28 Memorandumului Street \\ 400114 Cluj-Napoca, Romania \\ Email: ${ }^{a}$ ruben.crisan@aut.utcluj.ro

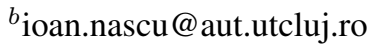

\author{
Eveline Volcke \\ Ghent University \\ Coupure Links 653 Bl. A \\ B9000 Gent, Belgium \\ Email: eveline.volcke@ugent.be
}

\author{
Robin De Keyser \\ Ghent University \\ Technologiepark 913 \\ B9052 Zwijnaarde, Belgium \\ Email: robain.dekeyser@ugent.be
}

\begin{abstract}
Predictive control is one of the most spread advanced control algorithms in industrial application field. Extended Prediction Self-Adaptive Control (EPSAC) is a part of this family of algorithms and is suitable for wastewater treatment plants control. The main goal of those industrial processes is to fulfil effluent water quality legal provisions with minimal energy consumption. In order to achieve this goal EPSAC control methodology has been applied to the wastewater treatment process. Benchmark Simulation Model No. 1 (BSM1) has been used to simulate the process dynamics. Two types of control strategies were implemented and tested: predictive control without taking into account measured disturbances and predictive control with feedforward. Feedforward control with two measured disturbances (the influent flow rate and ammonium concentration) has been tested.
\end{abstract}

Index Terms-wastewater, predictive control, EPSAC, benchmark simulation model, BSM1

\section{INTRODUCTION}

Due to the complexity of physical, chemical and biological processes that comprise wastewater treatment technology the control of those industrial plants is difficult. Many parameters with different nature, the seasonal, diurnal and hourly continuous variation of parameters, complexity of biological reactions takes place and the limited number of variables that can be manipulated, contribute also at the complexity of the process. Thus, is difficult to control a sum of uniform processes influence each other. Over time have been proposed in the literature various control strategies of wastewater treatment plants with different goals [1], [2], [3]. Their evaluations and comparisons are very difficult and almost non-existent. Many control strategies have been the objective to control dissolved oxygen [2], [4]. Further control algorithms are focused also on nitrate control [6], [7], [8] or extend the control strategy on whole plant and to the sewer system using heretical model predictive control [1]. The methods approached are also various: Proportional Integral and Derivative (PID) control, or feedforward integrated with feedback control [9], model predictive control (MPC) [4], [1], [10], [11], optimal control [13], fuzzy control [12] and nonlinear control. Experimental validation of those control strategies are few [14] due to the difficulty of applying those control algorithms on operational and running plants and also due to the lack of some parameters measurement.
MPC has been implemented on complex nonlinear industrial processes [15] and is suitable for applying to wastewater treatment processes. In [4] was also implemented dissolved oxygen control of the activated sludge system using MPC. The goal of MPC is to maintain the process output variables at setpoints with respecting the constraints that are naturally included in the strategy. Compliance with legal provisions related to discharge water quality standards is the first objective of MPC control [17]. The second objective is reducing operational costs [14] that are mainly generated by pumping and blowing. Thus, is very important to maintain a correlation between this two goals. This paper is organized as follows: these benchmark is briefly described in second section, followed by EPSAC approach to MPC for wastewater treatment control in third section. The identification is done in fourth section, while the fifth section presents the results.

\section{BENCHMARK DESCRIPTION}

In [1] is noticed that a synthesis of the control structure for wastewater treatment process is very complicated, because of its specific features. Those features include: (i) multiple time scales variations of parameters in the biological process, (ii) influent flow rates variations and pollutant concentrations, (iii) non-linearity of the process, (iv) biological sustainability assurance in spite of unknown disturbances, (v) high disturbances amplitude with hard influence to the biological process, (vi) the small number of measurable variables due to lack of sensors [1].

The lack of wastewater treatment process models implementation from literature are partially solved with development of the Benchmark Simulation Model No.1 (BSM1). It consists of five biological reactors connected in series, from which the first two are anoxic and the last three are aerated reactors and two recirculating loops: internal recycle from the last to the first reactors and external recycle, from the secondary settler to the first reactor [16]. The reactors are modelled according to the Activated Sludge Model No. 1 (ASM1) presented in 1987 by Henze et. al [19]. The ASM1 has thirteen state variables and eight dynamic processes and it consists of a set of ordinary differential equations which describe the dynamic changes of the state variables. A schematic representation of the plant is presented in Figure 1. 


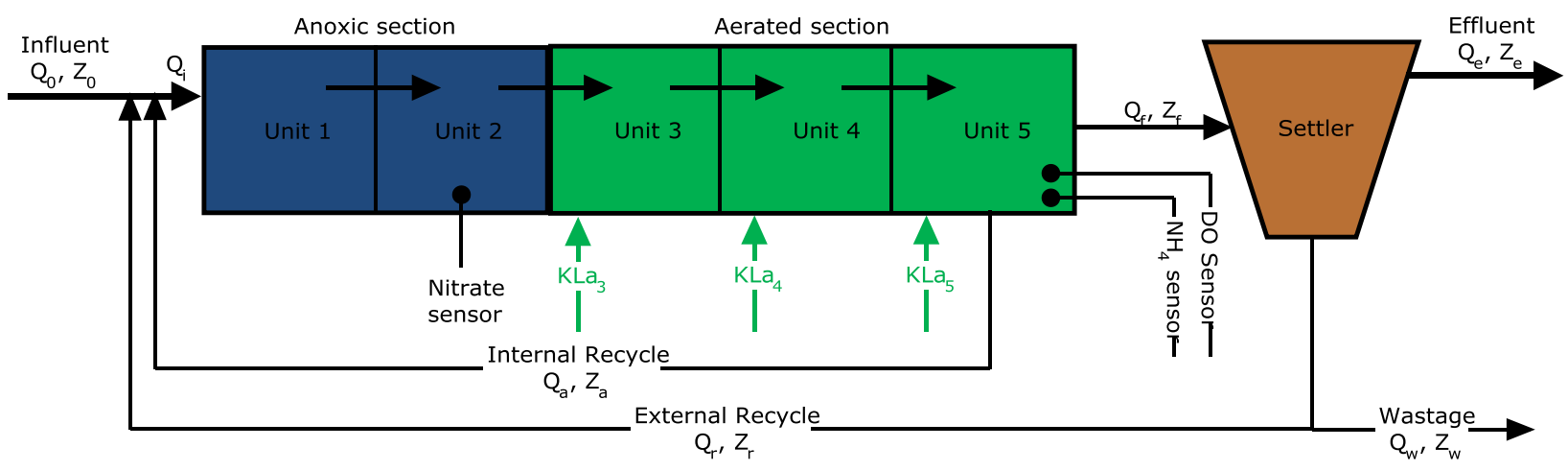

Fig. 1. BSM1 benchmark layout

The BSM1 is characterized by a high degree of flexibility, allowing for approximately 30 different control handles and a wide variety of sensors. The performance criteria can be divided in two categories: the process performance and the control loop performance. The process performance refers to the effect of the control strategy on the plant in terms of effluent quality, while the control loop performance estimates the effect of a control strategy in terms of wear and tear of actuators, controller robustness, disturbance attenuation, etc. After the publication of the first version by the IWA Task Group on Respirometry, the work at the BSM1 continued in Europe within the COST Actions 682 and 624 until COST Action 624 ended in June 2004. The input - output scheme of the wastewater treatment, that is used in current work, is represented in figure 2 . The manipulated variables are oxygen mass transfer coefficients in reactors $K L a_{3}, K L a_{4}, K L a_{5}$ and internal recirculation flow rate, $Q_{i} n t r$. The measured disturbances are influent flow rate, $Q_{0}$, and influent ammonium concentration, $[\mathrm{NH}]_{0}$. The controlled outputs are ammonium concentration in the fifth reactor and nitrate concentration in the second reactor. The influent and effluent are described by the flow rate, $Q_{0}$, respectively $Q_{e}$ and components concentrations $Z_{0}$, respectively $Z_{e}$.

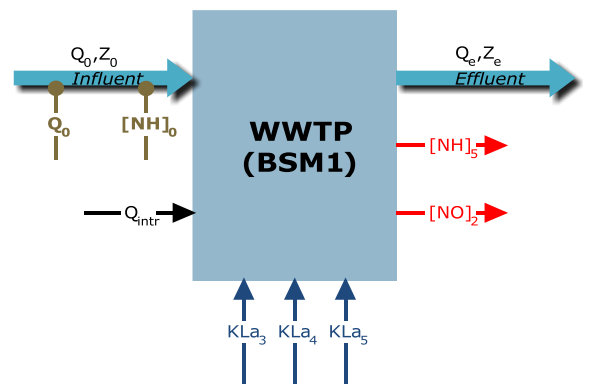

Fig. 2. Input-output scheme

\section{EPSAC APPROACH TO MPC}

Model Based Predictive Control (MBPC) is a control strategy developed around two main principles: on-line use of a process model to predict the process output at future moments and compute of an optimal control action based on the minimization of cost function(s), with constraints on the process variables. [18]. From the various algorithms of MBPC family EPSAC is differences by the type of the process model and its disturbances and the cost function(s) to be minimized, with/without constraints. The control algorithms are based on [18]. The process model is represented as:

$$
y(t)=x(t)+n(t)
$$

where the disturbance $n(t)$ includes all effects in the measured output $y(t)$ which do not come from the model output $x(t)$. It includes effects of process disturbances, other (unmodeled) process inputs, measurement noise, model errors, etc. The combination of all these non-measurable disturbances has a stochastic character with non-zero average value. It can be modeled by a colored noise process:

$$
n(t)=\frac{C\left(q^{-1}\right)}{D\left(q^{-1}\right)} e(t)
$$

Where $e(t)$ is the uncorrelated noise with zero mean value (white noise), $C\left(q^{-1}\right), D\left(q^{-1}\right)$ monic polynomials of order nc and nd. The filter $C\left(q^{-1}\right) / D\left(q^{-1}\right)$ is the disturbance model and is used to eliminate the steady-state disturbances, to suppress disturbances at specific frequencies and to increase robustness of controller [18]. The effect of the process input $u(t)$ on the process output $y(t)$ is represented by the model output $x(t)$.

The relationship between $u(t)$ and $x(t)$ is represented by the dynamic model:

$$
x(t)=\mathrm{f}[x(t-1), x(t-2), \cdots, u(t-1), u(t-2), \cdots]
$$

where $f$ represent a known function. The prediction of the process output $y(t+k / t), k=1 \ldots N_{2}$ is based on measurements available at time t. Using the process model, the forward relation is obtain:

$$
y(t+k / t)=x(t+k / t)+n(t+k / t)
$$


The aim of the predictive controller is to find the control vector $u(t+k / t), k=0 \ldots N_{2}$ which minimizes the cost function

$$
\sum_{k=N_{1}}^{N_{2}}[r(t+k \mid t)-y(t+k \mid t)]^{2}+\lambda \sum_{k=0}^{N_{u}-1}[\Delta u(t+k \mid t)]^{2}
$$

The controller design parameters are: $N_{2}=$ the prediction horizon (default $N_{2}=N_{1}+1 \ldots N_{1}+10$ ), $N_{u}$ = the control horizon (default $N_{u}=1$ ), $N_{1} \ldots N_{2}=$ the coincidence horizon (default $N_{1}=$ time-delay), $\gamma=$ weight parameter (default 0 ) and $\alpha=$ filter parameter (default 0 ). The signal $r($.$) is the reference$ trajectory. The future response $y(t+k / t)$ that is composed as sum of two effects:

$$
y(t+k \mid t)=y_{\text {free }}(t+k \mid t)+y_{\text {forced }}(t+k \mid t)
$$

The first term include the effect of past control, the effect of a default future control scenario and the effect of future disturbances. The second term represents the effect of future control actions:

$$
\left\{\Delta u(t \mid t), \Delta u(t+1 \mid t), \ldots \Delta u\left(t+N_{u}-1 \mid t\right)\right\}
$$

The component $y_{\text {forced }}(t+k / t)$ represents the effect of a step inputs sequence. The cumulative effect of all steps is:

$$
\begin{aligned}
& y_{\text {forced }}(t+k \mid)=g_{k} \Delta u(t \mid t)+g_{k-1} \Delta(t+1 \mid t)+\ldots \\
& \ldots+g_{k-N_{u}+1} \Delta\left(t+N_{u}-1 \mid t\right)
\end{aligned}
$$

Where the parameters $g_{1}, g_{2}, \ldots g_{k}, \ldots g_{N}$ are the coefficients of the unit step response of the system, i.e. the response of the system output for a stepwise change of the system input. These step response coefficients can be computed by sending a step into the process model: $\mathbf{Y}_{\text {forced }}=\mathbf{G U}$, leading to the key MPC equation:

$$
\mathbf{Y}=\overline{\mathbf{Y}}+\mathbf{G} \mathbf{U}
$$

with the notation:

$$
\left\{\begin{array}{l}
\mathbf{Y}=\left[y\left(t+N_{1} \mid t\right) \ldots y\left(t+N_{2} \mid t\right)\right]^{T} \\
\mathbf{R}=\left[r\left(t+N_{1} \mid t\right) \ldots r\left(t+N_{2} \mid t\right)\right]^{T} \\
\overline{\mathbf{Y}}=\left[y_{\text {free }}\left(t+N_{1} \mid t\right) \ldots y_{\text {free }}\left(t+N_{2} \mid t\right)\right]^{T} \\
\mathbf{U}=\left[\Delta u(t \mid t) \ldots \Delta u\left(t+N_{u}-1 \mid t\right)^{T}\right.
\end{array}\right.
$$

Using the above notation, the cost function is:

$$
\begin{array}{r}
(R-Y)^{T}(R-Y)+\lambda U^{T} U= \\
{[(R-\bar{Y})-G U]^{T}[(R-\bar{Y})-G U]+\lambda U^{T} U}
\end{array}
$$

This is a quadratic form in $U$. Minimization w.r.t. $U$ gives the optimal solution (with $I$ the identity matrix):

$$
U^{*}=\left(G^{T} G+\lambda I\right)^{-} 1 G^{T}(G-\bar{Y})
$$

Only the first element $\Delta u(t / t)$ in $U^{*}$ is needed in order to calculate the actual control input:

$$
u(t)=u(t-1)+\Delta u(t \mid t)
$$

At the next sampling instant $t+1$, the whole procedure is repeated taking into account the new measurement information $y(t+1)$. This procedure is called the 'receding horizon' principle of MPC. The matrix $[G T G+\lambda I]$ which has to be inverted has dimension $N_{u}$ x $N_{u}$. For the default case of $N_{u}=1$, this results in a scalar control law.

\section{LINEAR MODEL IDENTIFICATION}

The input signal for identification was chosen taking into account that the PRBS signal can capture better the dynamic of the process in comparison with a step signal. The identification signal is a Pseudo Random Binary Sequence (PRBS) and sampling time period is $0.5 \mathrm{~h}$. Maximum frequency of PRBS signal is 48 days $^{-1}$ and the minimum frequency is 6 days $^{-1}$. This PRBS signal, with appropriate scaling, was used for the identification of all processes. System response was achieved by applying the PRBS signal to each input and measured disturbance from time 100 days, that was considered the time need for achieve the system steady state values. It was establish that the PRBS signal tine of 10 days for capture process dynamics is enough. Was achieved system response for inputs: oxygen mass transfer coefficients for reactors 3,4 and $5\left(K_{L a 3}, K_{L a 4}, K_{L a 4}\right)$, internal recirculate flow rate $\left(Q_{i n t r}\right)$

\begin{tabular}{|c|c|c|}
\hline $\begin{array}{l}\text { Transfer } \\
\text { Function }\end{array}$ & $\begin{aligned} \text { Process model: } \\
y(t)=\left[B\left(q^{-1}\right) / A\left(q^{-1}\right)\right] u(t)+e(t)\end{aligned}$ & $\begin{array}{l}\text { FIT } \\
{[\%]}\end{array}$ \\
\hline $\mathrm{H}_{\mathrm{NH} 5 \mathrm{KL}, \mathrm{a3}}$ & $\begin{array}{l}\mathrm{B}\left(\mathrm{q}^{-1}\right)=-0.0009346 \mathrm{q}^{-1}+0.0001578 \mathrm{q}^{-2}+0.001033 \mathrm{q}^{-3}-0.0002565 \mathrm{q}^{-4} \\
\mathrm{~A}\left(\mathrm{q}^{-1}\right)=1-1.969 \mathrm{q}^{-1}+1.204 \mathrm{q}^{-2}-0.2939 \mathrm{q}^{-3}+0.05885 \mathrm{q}^{-4}\end{array}$ & 87.03 \\
\hline $\mathrm{H}_{\mathrm{NHSKLa4}}$ & $\begin{array}{l}\mathrm{B}\left(\mathrm{q}^{-1}\right)=-0.002086 \mathrm{q}^{-1}+0.002366 \mathrm{q}^{-2}-2.91 \mathrm{e}-005 \mathrm{q}^{-3}-0.0002511 \mathrm{q}^{-4} \\
\mathrm{~A}\left(\mathrm{q}^{-1}\right)=1-1.73 \mathrm{q}^{-1}+0.7214 \mathrm{q}^{-2}-0.01118 \mathrm{q}^{-3}+0.01929 \mathrm{q}^{-4}\end{array}$ & 88.80 \\
\hline $\mathrm{H}_{\mathrm{NHSKL} \text {.as }}$ & $\begin{array}{l}B\left(q^{-1}\right)=-0.01014 q^{-1}+0.01461 q^{-2}-0.004871 q^{-3}+0.000399 q^{-4} \\
A\left(q^{-1}\right)=1-1.726 q^{-1}+0.7786 q^{-2}-0.09957 q^{-3}+0.04714 q^{-4}\end{array}$ & 88.46 \\
\hline $\mathrm{H}_{\mathrm{NH} 5 \mathrm{Qintr}}$ & $\begin{array}{l}B\left(q^{-1}\right)=2.111 e-005 q^{-1}-3.252 e-005 q^{-2}+3.504 e-006 q^{-3}+7.907 e-006 q^{-4} \\
A\left(q^{-1}\right)=1-1.91 q^{-1}+1.113 q^{-2}-0.2524 q^{-3}+0.04959 q^{-4}\end{array}$ & 95.66 \\
\hline $\mathrm{H}_{\mathrm{NH}[\mathrm{NH}] 0}$ & $\begin{array}{l}B\left(q^{-1}\right)=0.009748 q^{-1}+0.01735 q^{-2}-0.02162 q^{-3}-0.005481 q^{-4} \\
A\left(q^{-1}\right)=1-2.155 q^{-1}+1.616 q^{-2}-0.5944 q^{-3}+0.1337 q^{-4}\end{array}$ & 87.99 \\
\hline $\mathrm{H}_{\mathrm{NH} 5[\mathrm{Q}] 0}$ & $\begin{array}{l}\mathrm{B}\left(\mathrm{q}^{-1}\right)=3.217 \mathrm{e}-005 \mathrm{q}^{-1}-1.117 \mathrm{e}-005 \mathrm{q}^{-2}-2.987 \mathrm{e}-005 \mathrm{q}^{-3}+8.868 \mathrm{e}-006 \mathrm{q}^{-4} \\
\mathrm{~A}\left(\mathrm{q}^{-1}\right)=1-2.65 \mathrm{q}-1+2.674 \mathrm{q}-2-1.327 \mathrm{q}-3+0.3033 \mathrm{q}-4\end{array}$ & 88.44 \\
\hline $\mathrm{H}_{\mathrm{N} O 2 K L \mathrm{~K} 5}$ & $\begin{array}{l}B\left(q^{-1}\right)=0.003546 q^{-1}-0.002238 q^{-2}-0.003783 q^{-3}+0.002474 q^{-4} \\
A\left(q^{-1}\right)=1-2.302 q^{-1}+1.702 q^{-2}-0.4627 q^{-3}+0.06309 q^{-4}\end{array}$ & 95.92 \\
\hline $\mathrm{H}_{\mathrm{NO} \text { Q }}$ intr & $\begin{array}{l}B\left(q^{-1}\right)=4.469 e-005 q^{-1}-3.831 e-005 q^{-2}+7.02 e-006 q^{-3}+3.129 e-006 q^{-4} \\
A\left(q^{-1}\right)=1-1.14 q^{-1}+0.4646 q^{-2}-0.09085 q^{-3}+0.01625 q^{-4}\end{array}$ & 95.66 \\
\hline $\left.\mathrm{H}_{\mathrm{N} O 2[\mathrm{NH}]}\right]$ & $\begin{array}{l}B\left(q^{-1}\right)=-0.0003256 q^{-1}+0.002409 q^{-2}-0.002167 q^{-3}+8.505 e-005 q^{-4} \\
A\left(q^{-1}\right)=1-2.856 q^{-1}+2.792 q^{-2}-1.009 q^{-3}+0.07357 q^{-4}\end{array}$ & 80.60 \\
\hline $\mathrm{H}_{\mathrm{NO} 2[\mathrm{Q}] 0}$ & $\begin{array}{l}\mathrm{B}\left(\mathrm{q}^{-1}\right)=-7.605 \mathrm{e}-005 \mathrm{q}^{-1}+6.006 \mathrm{e}-005 \mathrm{q}^{-2}-4.24 \mathrm{e}-006 \mathrm{q}^{-3}+2.024 \mathrm{e}-005 \mathrm{q}^{-4} \\
\mathrm{~A}\left(\mathrm{q}^{-1}\right)=1-1.59 \mathrm{q}^{-1}+0.7111 \mathrm{q}^{-2}-0.436 \mathrm{q}^{-3}+0.3152 \mathrm{q}^{-4}\end{array}$ & 84.40 \\
\hline
\end{tabular}
and measured disturbances: influent ammonium concentration $\left([N H]_{0}\right)$ and influent flow rate $\left([Q]_{0}\right)$. The outputs of the system are the ammonium concentration in the tank 5 and nitrate concentration in tank 2 . The influence of oxygen mass transfer coefficients change in reactor 3 and 4 to nitrate concentration from reactor 2 is neglectable. In table 1 are presented the transfer function obtained together with the corresponding FIT values for each model. All models were obtained using discrete

TABLE I

BSM1 IDENTIFICATION

transfer function represented as a ratio of two polynoms of 4th order. Estimation of models was made for $70 \%$ of the data obtained and for the rest of $30 \%$ the validation was realized. The rate of success (i.e. the matching of the dates obtained and the model) is between $80.60 \%$ and $95.66 \%$. Effluent ammonium concentration is the most sensitive output of the system together with total nitrogen concentration. For a linear system, the model parameters are independent to the amplitude of input step. But in this case, the system are nonlinear. To demonstrate this the static characteristic for dissolved oxygen and ammonium concentrations in tank 5 depending on the oxygen mass transfer coefficient of oxygen from the same tank $\left(K_{L a 5}\right)$ are presented in figure 5. It can be notice that the 


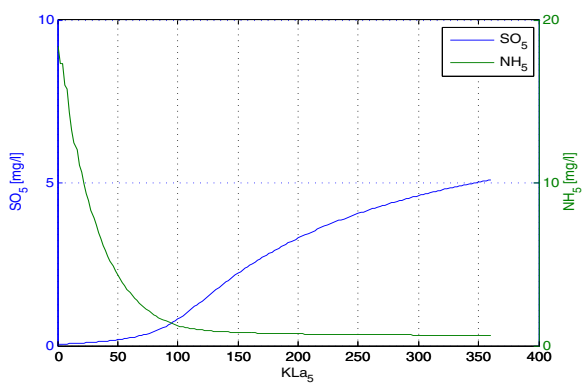

Fig. 3. Static characteristic

input amplitude has a big influence through process output and implicitly through the model obtained. For the improvement of control performances were taken into account two measurable disturbances. Because the influent ammonium concentration $[\mathrm{NH}]_{0}$ is the most sensitive input of the process, this play an important role and it is considered a measurable disturbance in the system. The second measurable disturbance is the influent flow rate $[Q]_{0}$. In practice the influent ammonium concentration disturbances and the influent flow rate varies between $[-31 \% \ldots 56 \%]$ and respectively $[-46 \% \ldots 74 \%]$ around the steady state values. As a result the identification signal amplitude is modifying with $+/-5 \%$ around the steady state value.

The EPSAC and EPSAC-FF (EPSAC with feedforward) strategies were tested in order to maintain the effluent quality when varying the influent flow rate and concentration. In figure 2 the system control scheme is presented. This scheme are designed taking into account EPSAC feedforward but in the case of EPSAC without feedforward, the scheme is not include disturbance measurement and feedforward control part. Table 2 presents the limits and fixed references for ammonium concentration, the total nitrogen concentration. The quality parameters of the effluent are: ammonium concentration $\left(S_{N H}\right)$, total nitrogen concentration $\left(N_{t o t}\right)$, total suspended solids (TSS), BOD 5 and $C O D$. The two controlled variables are ammonium concentration in tank 5 and nitrogen concentration in tank 2 and the four manipulated variables are: the mass transfer coefficients of oxygen from aerated tanks 3, 4 and 5 $\left(K_{L a 3}, K_{L a 4}\right.$ and $\left.K_{L a 5}\right)$ and the recirculation debit $\left(Q_{\text {intr }}\right)$. The setpoints for MPC strategy were established takes into account the discharged water quality limits. Table 2 shows that the limits are under variables prescripted bounds in order to keep the outputs of the system under bounds in majority of time. The conclusions of the experiments are that ammonium concentration and total nitrogen varies in similar way and are most affected to the disturbances occurrence, thus are considered the most sensitive variables of the system.

The simulation were realized using real data of operation from BSM1. The data correspond to three types of weather: dry, storm and rain with the sampling time is $0.25 \mathrm{~h}$. The prediction horizon $\mathrm{N}_{2}$ is one of the most important parameters in design of the medel predictive controller. The $N_{2}$ value
TABLE II

SET POINTS AND BOUNDS FOR THE CONTROLLED OUTPUTS

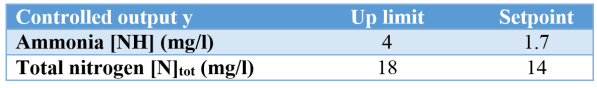

is set at 3 for the following control strategies EPSAC-FB3-1.7, EPSAC-FF-NH0-3-1.7, EPSAC-FF-Q0-3-1.7, EPSACFF-3-1.7 and EPSAC-FF-3-2.5. The controller sampling time is $0.5 \mathrm{~h}$. Also have been tested and other values for the prediction horizon: $N_{2}=10,48$ and 96 , but for $N_{2}=3$ were obtained the best control performances. Many different simulation have been performed with different EPSAC feedback controllers or combined feedforward-feedback controllers. Some of these control strategies are summarized in table 3 .

TABLE III

CONTROL STATEGIES

\begin{tabular}{|l|l|c|c|c|}
\hline \multicolumn{1}{|c|}{ Strategy } & \multicolumn{1}{|c|}{ Description } & $\mathbf{N}_{\mathbf{2}}$ & $\mathbf{S}_{\mathbf{N H} \text { spint }}$ & $\mathbf{S}_{\mathbf{N O} \text { spint }}$ \\
\hline EPSAC-FB-3-1.7 & EPSAC without feedforward & 3 & 1.7 & 3.7 \\
\hline EPSAC-FF-NH0-3-1.7 & $\begin{array}{l}\text { EPSAC with feedforward for influent } \\
\text { ammonium concentration disturbance }\end{array}$ & 3 & 1.7 & 3.7 \\
\hline EPSAC-FF-Q0-3-1.7 & $\begin{array}{l}\text { EPSAC with feedforward for influent } \\
\text { flow rate disturbance }\end{array}$ & 3 & 1.7 & 3.7 \\
\hline EPSAC-FF-3-1.7 & & 3 & 1.7 & 3.7 \\
\hline EPSAC-FF-10-1.7 & \multirow{2}{*}{\begin{tabular}{l} 
EPSAC with feedforward for influent \\
\cline { 1 - 1 } EPSAC-FF-48-1.7
\end{tabular}} & 10 & 1.7 & 3.7 \\
\hline EPSAC-FF-96-1.7 & influent flow rate disturbances & 96 & 1.7 & 3.7 \\
\hline EPSAC-FF-144-1.7 & & 144 & 1.7 & 3.7 \\
\hline EPSAC-FF-3-2.5 & & 3 & 2.5 & 3.7 \\
\hline
\end{tabular}

\section{RESULTS AND DISSCUSION}

The simulation procedure was done using Matlab Simulink benchmark implementation and standard BSM1 configuration parameters. The differential equations were integrated with a 5th-order Runge-Kutta with fixed integration step of 0.005 hours. Independently to the benchmark implementation the EPSAC algorithm was designed in a Matlab script. Control sampling time was $0.5 \mathrm{~h}$. Figure 6 presents the simulation sequence: (i) an open loop stabilization period using default benchmark constant inputs (period 1), (ii) a closed loop stabilization period in absence of disturbances (period 2), (iii) two closed loop dynamic periods in presence of disturbances, using default dry weather disturbance file from BSM1. In period 3 takes place system stabilisation and and for control performances assessment period 4 was considered.

Two predictive control strategies were implemented: one without disturbances compensation and one including disturbances compensation.

\section{A. Feedback control}

The process has two controlled outputs: ammonium concentration in tank $5\left([\mathrm{NH}]_{5}\right)$ (figure 7) and nitrate concentration in tank $2\left(\left[\mathrm{NO}_{2}\right)\right.$ (figure 8 ) and four manipulated inputs: oxygen mass transfer coefficients in tanks 3,4 and $5\left(K_{L a_{3}}, K_{L a 4}\right.$ and $\left.K_{L a 5}\right)$ and internal recirculation flow rate $\left(Q_{\text {intr }}\right)$. The controller task is considerable increased when the strong disturbance occurs in the system (after $\mathrm{t}=140$ days). The outputs 


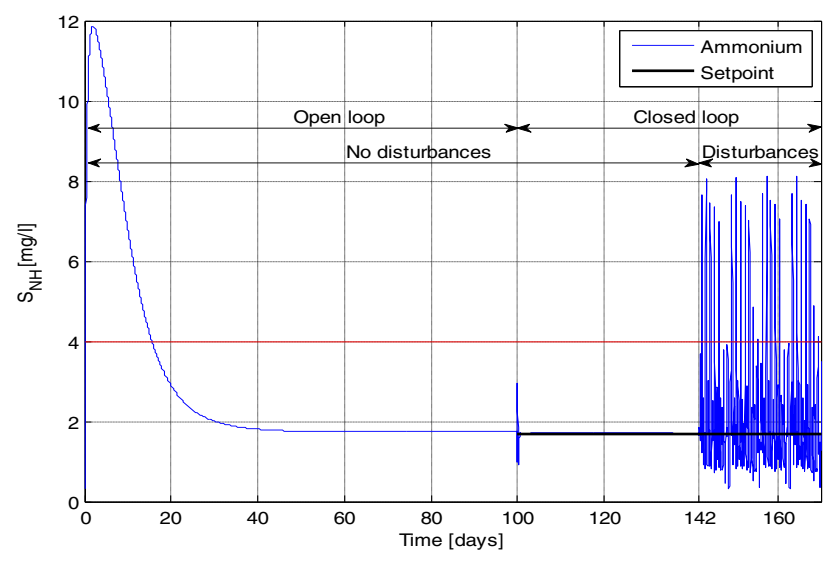

Fig. 4. Simulation sequence

become more sensitive to the inputs, including disturbances. Disturbances appearance, in influent pollutants concentrations and influent flow rate, have a major influence to the discharged water parameters quality.

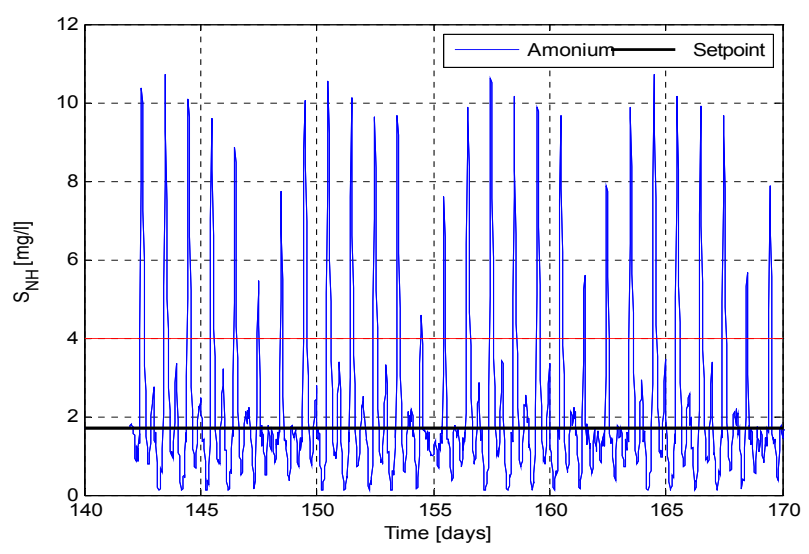

Fig. 5. Ammonium concentration in tank 5

\section{B. Feedforward control}

A feedforward controller has been designed using information from measured disturbances as model predictive controller. It was added to initial control system in order to improve its control performance. Results a multivariable feedforward-feedback controller, noted in the flowing as feedforward controller. Tree different feedforward controllers were designed, according with the disturbances takes into account: the influent ammonium concentration and the influent flow rate and both.

\section{Performance assessment}

Performances assessment was realized taking into account the medium value of effluent concentration in the evaluation period [156 170] days. Effluent ammonium and total nitrogen concentrations are the main outputs that has to be tracked. The most important disturbance that has to be compensated

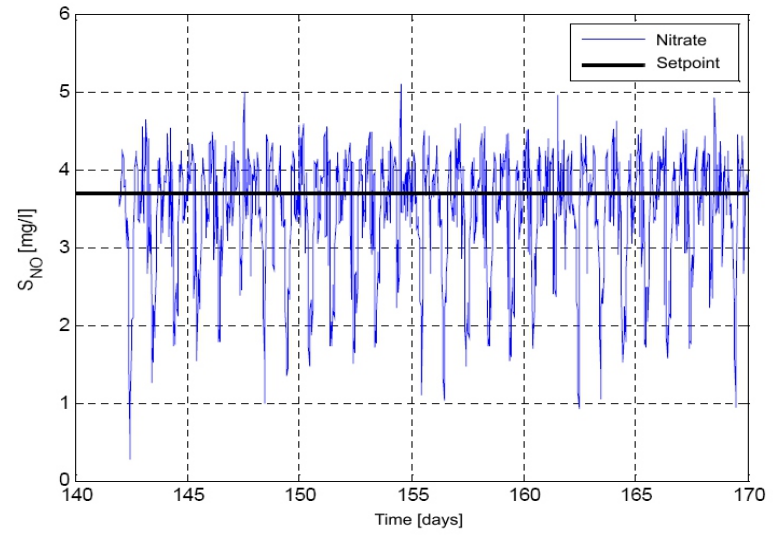

Fig. 6. Nitrate concentration in tank 2

is influent ammonium concentration $[\mathrm{NH}]_{0}$. Figures 10 and 11 represent a comparison between different EPSAC control strategies regarding manipulated variables: the ammonium concentration in tank 5 (figure 9) and nitrogen concentration in tank 2 (figure 10). When the feedforward controller is used for both disturbances (ammonium concentration $[\mathrm{NH}]_{0}$ and influent flow rate $[Q]_{0}$ ) the process performance improvement, regarding discharged water quality, is visible as it can be notice in figures 11 and 12. Forward color legend are used in the below figures: black line for EPSAC-FB-3-1.7 control strategy, blue line for EPSAC-FF-NH0-3-1.7 control strategy, green line for EPSAC-FF-Q0-3-1.7 control strategy, magenta line for EPSAC-FF-3-1.7 control strategy.

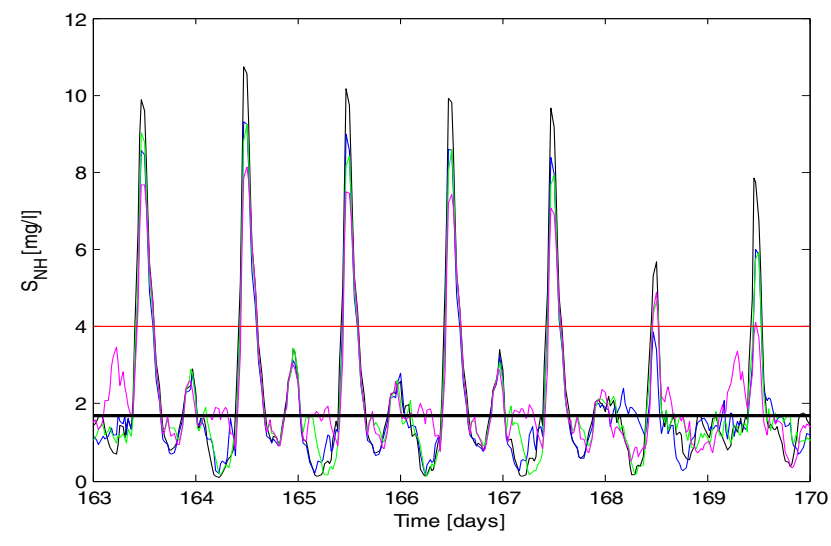

Fig. 7. Ammonium concentration in tank 5

\section{CONCLUSIONS}

This paper outlines the results of EPSAC strategy using BSM1 simulation benchmark of wastewater treatment plant. The major objective of this paper is the implementation of EPSAC control strategy for BSM1 platform. For the improvement of the control performances two measurable disturbances were considered (influent ammonium concentration and influent flow rate). Two EPSAC strategies were implemented: 


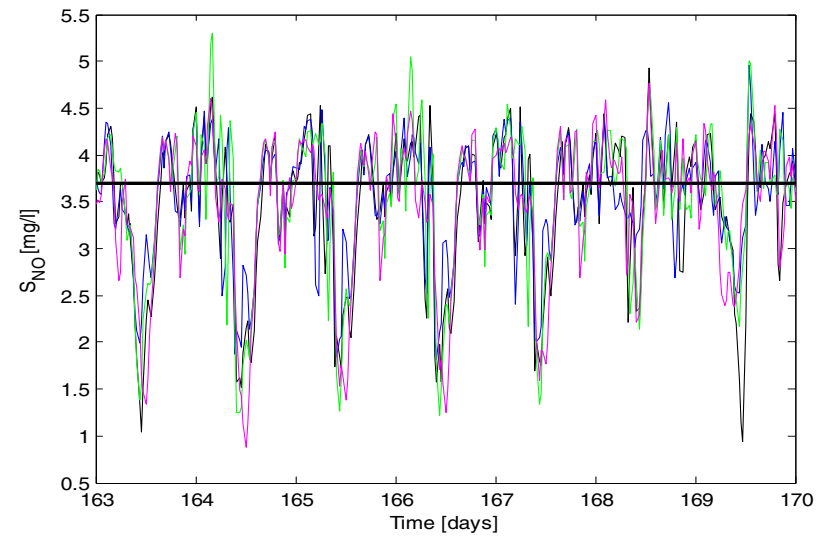

Fig. 8. Nitrogen concentration in tank 2

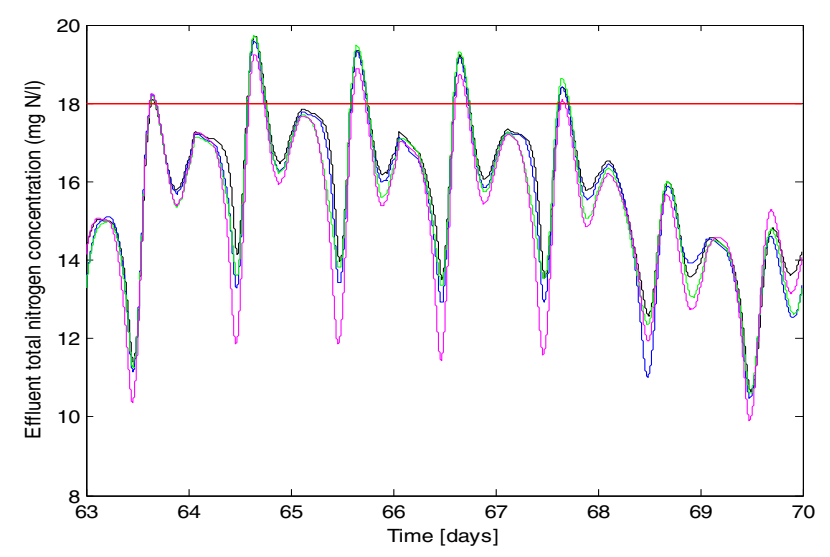

Fig. 9. Effluent total nitrogen concentration

EPSAC with disturbances compensation and EPSAC without disturbances compensation. Two measured disturbances were used in feedforward control strategy: the influent flow rate and the influent ammonium concentration. It is emphasised that the quality water achieved with feedforward control using the influent ammonium concentration disturbance signal is much higher than for the feedforward control using the influent flow rate disturbance signal and the feedforward control using both measured disturbances signals have the best control performances.

\section{ACKNOWLEDGMENT}

This work was supported by a grant of the Romanian National Authority for Scientific Research, CNDI-UEFISCDI, project number 274/09.09.2014.

\section{REFERENCES}

[1] M.A. Brdys, M. Grochowski, T. Gminski, K. Konarczak, M. Drewa (2008) Hierarchical predictive control of integrated wastewater treatment systems, Control Eng. Pract. 16 (6) 751-767.

[2] W. Chotkowski, M.A. Brdys,K.Konarczak (2005) Dissolved oxygen control for activated sludge process, Int. J. Syst. Sci. 36 (12) 727-737.

[3] C. Cadet, J.F. Beteau, S. Carlos Hernandez (2004) Multicriteria control strategy for cost/quality compromise in wastewater treatment plants, Control Eng. Pract. 12 335-347.

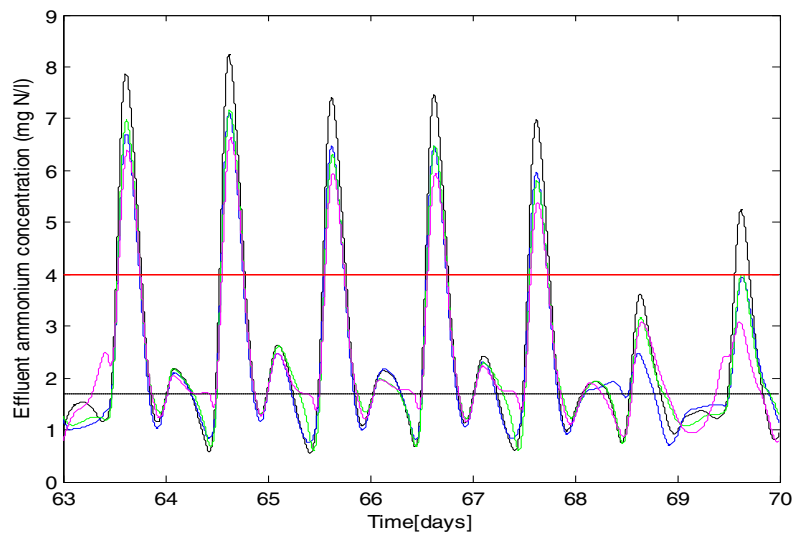

Fig. 10. Effluent ammonium concentration

[4] B. Holenda, E. Domokos, A. Redey, J. Fazakas (2007) Dissolved oxygen control of the activated sludge wastewater treatment process using model predictive control, Comp. Chem. Eng. 32 (6) 1270-1278.

[5] P.R. Barros, R. Carlsson (1998) Iterative design of a nitrate controller using an external carbon source in an activated sludge process, Water Sci. Technol. 37 (12) 95-101.

[6] A. Stare, D. Vrecko, N. Hvala, S. Strmcnik (2007) Comparison of control strategies for nitrogen removal in an activated sludge process in terms of operating costs: a simulation study, Water Res. 201441

[7] Z. Yuan, J. Keller (2003) Integrated control of nitrate recirculation and external carbon addition in a predenitrification system, Water Sci. Technol. 48 (1112) 345-354.

[8] B. Carlsson, A. Rehnstrom (2002) Control of an activated sludge process with nitrogen removala benchmark study, Water Sci. Technol. 45 (45) 135-142.

[9] D. Vrecko, N. Hvala, B. Carlsson (2003) Feedforward-feedback control of an activated sludge process: a simulation study, Water Sci. Technol. 47 (12) $19-26$.

[10] I. Satin, C. Predet, R. Vilanova (2015) Aplying variable dissolved oxygen set point in a two level hierarchical control structure to a wastewater treatment process, Journal of Process Control 28 40-45

[11] I. Satin, C. Predet, R. Vilanova, M. Meneses (2015) Removing violations of the effluent pollution in a wastewater treatment process, Chemical Engineering Journal 279 207-219

[12] S. Marsi-Libelli, L. Giunti (2002) Fuzzy predictive control for nitrogen removal in biological wastewater treatment, Water Sci. Technol. 45 (45) $37-44$.

[13] B. Chachuat, N. Roche, M.A. Latifi (2005) Optimal aeration control of industrial alternating activated sludge plants, Biochem. Eng. J. 23277 289

[14] E. Ayesa, A. De la Sota, P. Grau, J.M. Sagarna, A. Salterain, J. Suescun (2006) Supervisory control strategies for the new wwtp of Galido-Bilbao: the long run from the conceptual design to the full-scale experimental validation, Water Sci. Technol. 53 (45) 193-201.

[15] J. Richalet, A. Rault, J.L. Testud, J. Papon (1978) Model predictive heuristic control: applications to industrial processes, Automatica 14413 428

[16] J.B. Copp (ed.) (2002) The COST Simulation Benchmark. In Description and Simulator Manual. Office for Official Publications of the European Communities, Luxembourg.

[17] Wenhao Shen, Xiaoquan Chen, M.N. Pons, J.P. Corriou (2009). Model predictive control for wastewater treatment process with feedforward compensation, Chemical Engineering Journal, Volume 155, Issues 12, Pages 161174

[18] De Keyser, R. (2003). Model based predictive control for linear systems, chapter invited in UNESCO Encyclopaedia of Life Support Systems (EoLSS). Article contribution 6.43.16.1, Eolss Publishers Co Ltd, Oxford, $35 \mathrm{p}$.

[19] H.Henze, C.P.L.Jr. Grady, W. Gujer, G.V.R. Marais, T. Matsuo (1987) A general model for single sludge Wastewater Treatmant systems, Wat.Res. 21 (5) 505-515 